\title{
Effect of Stress Ratio(R) and Stress Concentration Factor (Kt) on Fatigue Properties of WSTi6211 Titanium Alloy
}

\author{
Hao Fang ${ }^{1,2}$, Feng Yong ${ }^{1,2}$, Du Yuxuan ${ }^{1}$, Wang Yue ${ }^{3}$, Xu Enen ${ }^{2}$, Wang Kaixuan ${ }^{2}$,Tian Yanwen ${ }^{2}$ \\ ${ }^{1}$ State Key Laboratory of Solidification Processing, Northwest Polytechnical University,Xi'an,Shaanxi 710072,China \\ ${ }^{2}$ Western Superconducting Technologies Co., Ltd., Xi'an,Shaanxi 710018, China \\ ${ }^{3}$ Xi' an University of Architecture and Technology, Xi'an,Shaanxi 710055, China \\ *Email: haofang85@163.com
}

\begin{abstract}
In this paper, the author studied the effects of different stress ratios $(\mathrm{R})$ and stress concentration factors $\left(\mathrm{K}_{\mathrm{t}}\right)$ on the fatigue properties of WSTi6211 titanium alloy.Through S-N curve, the author obtained the fatigue ultimate strength of the material under different conditions and analyzed characteristics of fatigue fractures, including the crack source, the crack growth region and the final rupture region. The results show that when $\mathrm{K}_{\mathrm{t}}=1, \mathrm{R}=0.5$, the fatigue ultimate strength $\sigma_{\mathrm{D}}$ is $626 \mathrm{MPa}$; when $\mathrm{K}_{\mathrm{t}}=1, \mathrm{R}=0.06$, the fatigue ultimate strength $\sigma_{\mathrm{D}}$ is $527.5 \mathrm{MPa}$; when $\mathrm{K}_{\mathrm{t}}=3, \mathrm{R}=0.06$, the ultimate fatigue strength $\sigma_{D}$ is $267 \mathrm{MPa}$. Fatigue performance is very sensitive to $\mathrm{R}$ and $\mathrm{K}_{\mathrm{t}}$. The larger $\mathrm{R}$ is, the larger the fatigue ultimate strength is. The larger Kt is, the smaller the fatigue limit strength is. The fracture morphology shows typical fatigue fracture morphology. Most of the cracks originate on the surface of specimens and have typical fatigue bands. With the decrease of stress, the area of crack growth zone increases.
\end{abstract}

Key words: WSTi6211 Titanium Alloy; S-N Curve; Stress Ratio; Stress Concentration Factor

\section{Intrpduction}

"A generation of materials, a generation of equipment". ${ }^{[1]}$ Titanium alloy is an advanced aviation material with a density of only $4.5 \mathrm{~g} / \mathrm{cm}^{3}$. It has excellent corrosion resistance, higher specific strength, good high temperature performance and fatigue resistance, and has become one of the main structural materials of modern aircraft. At present, the use of titanium alloys in aircraft has become one of the important indicators to measure its advancement. For example, the use of titanium alloys in F-22 of the fourth generation aircraft in the United States has reached $41 \%$. With the development of aviation technology, the requirement of combat performance, maneuverability, reliability and service life of aircraft has been improved, and the amount of high-end titanium alloys used in new aircraft will continue to increase.

WSTi6211, similar to TA15 titanium alloy, is a near-alpha titanium alloy with high $[\mathrm{Al}]_{\mathrm{eq}}$. It has medium room temperature and high temperature strength, good thermal stability and weldability. It is an important titanium alloy material for aircraft and can be used for a long time from $450{ }^{\circ} \mathrm{C}$ to $500^{\circ} \mathrm{C}^{[2]}$. Fatigue property of materials is usurally an important factor that directly affects their service life. There are many reports on the study of microstructure, fatigue properties and fracture behavior of titanium alloys. However, most literatures focus on the comparison of fatigue deformation characteristics between lamellar structure obtained by single-phase deformation and bimodal structure obtained by two-phase deformation ${ }^{[3-8]}$. However, the effect of $\mathrm{R}$ and $K_{t}$ on the equiaxed structure of the alloy has rarely been reported. In this paper, the effects of $\mathrm{Kt}$ and $\mathrm{R}$ on fatigue properties were studied, and the fracture morphology characteristics were analyzed, which lays a theoretical foundation for exploiting the potential application of materials.

\section{Material and experiments}

\subsection{Experimental Materials}

(C) The Authors, published by EDP Sciences. This is an open access article distributed under the terms of the Creative Commons Attribution License 4.0 (http://creativecommons.org/licenses/by/4.0/). 
The experimental material is WSTi6211 titanium alloy bar with $300 \mathrm{~mm}$ diameter. The chemical composition is shown in Table 1. The phase transformation temperature is $995 \pm 5{ }^{\circ} \mathrm{C}$. The heat treatment mode is $840 \mathrm{C} / 2.5 \mathrm{~h}, \mathrm{AC}$.

Table 1 The composition of WSTi6211

\begin{tabular}{c|c|c|c|c|c|c|c}
\hline s & $\mathrm{Al}$ & $\mathrm{Mo}$ & $\mathrm{V}$ & $\mathrm{Zr}$ & $\mathrm{Si}$ & $\mathrm{O}$ & $\mathrm{Ti}$ \\
\hline Wt.\% & 6.89 & 1.77 & 2.33 & 2.32 & 0.024 & 0.12 & Bal. \\
\hline
\end{tabular}

The microstructure of WSTi6211 titanium alloy bar is typical equiaxed structures processed in two-phase zone. The content of a phase is about $70 \%$ and the size is about $10-20 \mu \mathrm{m}$. Shown in Fig.1.

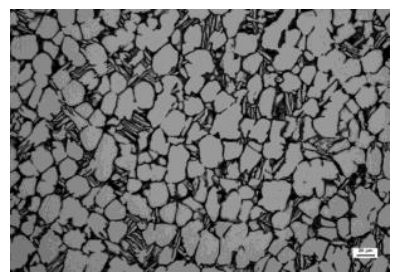

Fig.1 Microstructure of WSTi6211

\subsection{Experimental Method}

High cycle fatigue test was carried out on Zwick Amsler HFP 5100 high frequency fatigue testing machine. The frequency $\mathrm{f}$ is $120 \mathrm{~Hz}$, stress amplitude control with sine wave. When the minimum number of cycles is exceeds $1.0 \times 107$ times, if the sample is not broken, the test will be terminated artificially and the sample passed the test.

The testing process conforms to GB/T3075-2008 with atmospheric environment and RT. The high cycle fatigue properties of the alloy were tested by group method and lifting method, and the S-N curve was drawn. The conditional fatigue ultimate strength of the alloy was determined by lifting method formula. The sample size is shown in Fig.2.
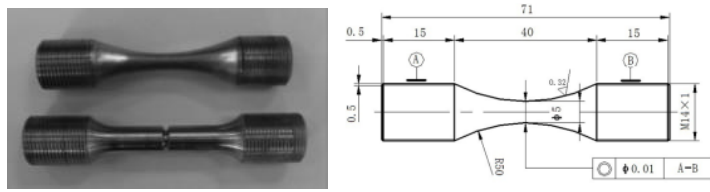

Fig.2 Size of sample

According to the design parameters of the alloy used in aeronautical structures, three groups of typical tests were designed in this experiment.
(1) $\mathrm{Kt}=1, \mathrm{R}=0.06$;
(2) $\mathrm{Kt}=1, \mathrm{R}=0.5$;
(3) $\mathrm{Kt}=3, \mathrm{R}=0.06$.

\subsection{Fracture Morphology Observation}

After the fatigue loading test, the fracture morphology of specimens under different loading conditions was observed by JSM4640 SEM. The characteristics of fatigue crack source, propagation zone and instantaneous fracture zone from high stress zone to low stress zone were observed. The sensitivity of the alloy to stress ratio and stress concentration factor was analyzed.

\section{Results}

\subsection{Fatigue Performance of $K_{t}=1, R=0.5$}

Under the test conditions of $\mathrm{K}_{\mathrm{t}}=1$ and $\mathrm{R}=0.5$, the median fatigue life corresponding to the maximum stresses of $1000 \mathrm{MPa}, 900 \mathrm{MPa}$ and $800 \mathrm{MPa}$ is $6.8 \times 10^{4}$ 、 $2.58 \times 10^{5}$ and $1.108 \times 10^{6}$ respectively. The fatigue ultimate strength was measured by lifting method. As shown in Table 2 and Fig.3, the maximum stress ranged from $600 \mathrm{MPa}$ to $660 \mathrm{MPa}$, which consisted of five pairs. The fatigue ultimate strength $\sigma_{\mathrm{D}}=626 \mathrm{MPa}$ and the $\mathrm{C}_{\mathrm{v}}$ was 0.0313 .

Table 2 Fatigue Performance $\left(\mathrm{K}_{\mathrm{t}}=1, \mathrm{R}=0.5\right)$
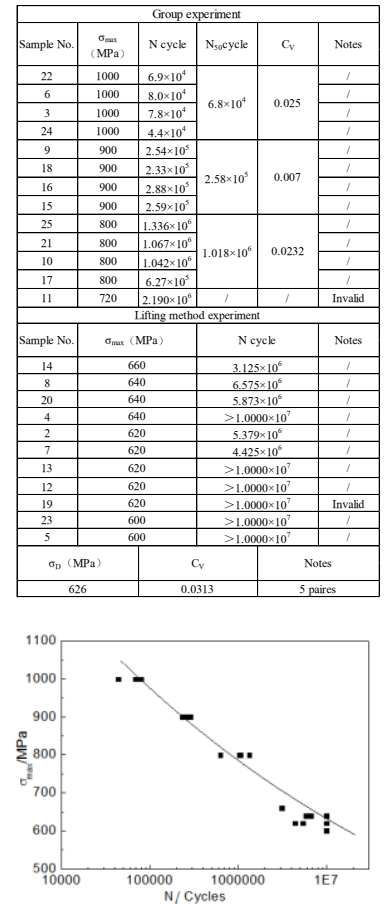

Fig $3 \mathrm{~S}-\mathrm{N}$ curve $\left(\mathrm{K}_{\mathrm{t}}=1, \mathrm{R}=0.5\right)$

\subsection{Fatigue Performance of $K_{t}=1, R=0.06$}

Under the test conditions of $K_{t}=1$ and $R=0.06$, the median fatigue life corresponding to the maximum stresses of $900 \mathrm{MPa}, 800 \mathrm{MPa}$ and $700 \mathrm{MPa}$ is $3.4 \times 10^{4}$ 、 $1.40 \times 10^{5}$ and $6.80 \times 10^{6}$ respectively. The fatigue ultimate strength was measured by lifting method. As shown in Table 3 and Fig.4, the maximum stress ranged from 500 $\mathrm{MPa}$ to $550 \mathrm{MPa}$, which consisted of five pairs. The fatigue ultimate strength $\sigma_{D}=527.5 \mathrm{MPa}$ and the $\mathrm{Cv}$ was 0.026 . 
Table 3 Fatigue Performance $\left(\mathrm{K}_{\mathrm{t}}=1, \mathrm{R}=0.06\right)$
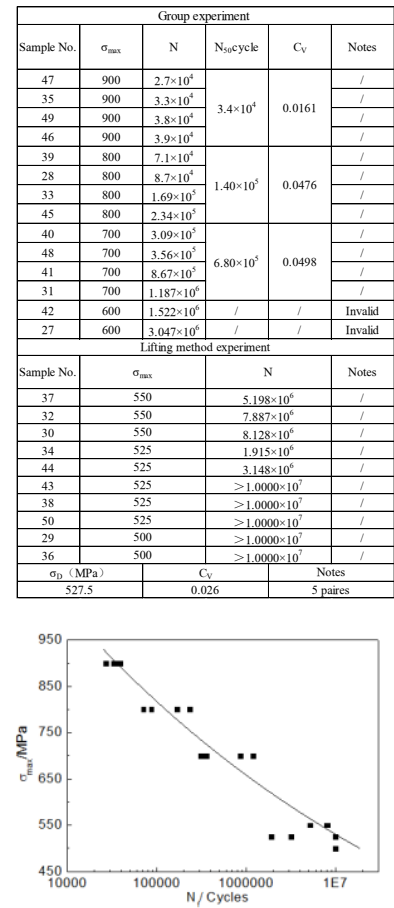

Fig 4 S-N curve $\left(\mathrm{K}_{\mathrm{t}}=1, \mathrm{R}=0.06\right)$

\subsection{Fatigue Performance of $K_{t}=3, R=0.06$}

Under the test conditions of $\mathrm{K}_{\mathrm{t}}=3$ and $\mathrm{R}=0.06$, the median fatigue life corresponding to the maximum stresses of $400 \mathrm{MPa}, 350 \mathrm{MPa}$ and $300 \mathrm{MPa}$ is $1.13 \times 10^{5}$ 、 $5.79 \times 10^{5}$ and $1.772 \times 10^{6}$ respectively. The fatigue ultimate strength was measured by lifting method. As shown in Table 4 and Fig 5, the maximum stress ranged from $250 \mathrm{MPa}$ to $280 \mathrm{MPa}$, which consisted of five pairs. The fatigue ultimate strength $\sigma_{\mathrm{D}}=267 \mathrm{MPa}$ and the $\mathrm{Cv}$ was 0.0313 .
Table 2 Fatigue Performance $\left(\mathrm{K}_{\mathrm{t}}=3, \mathrm{R}=0.06\right)$
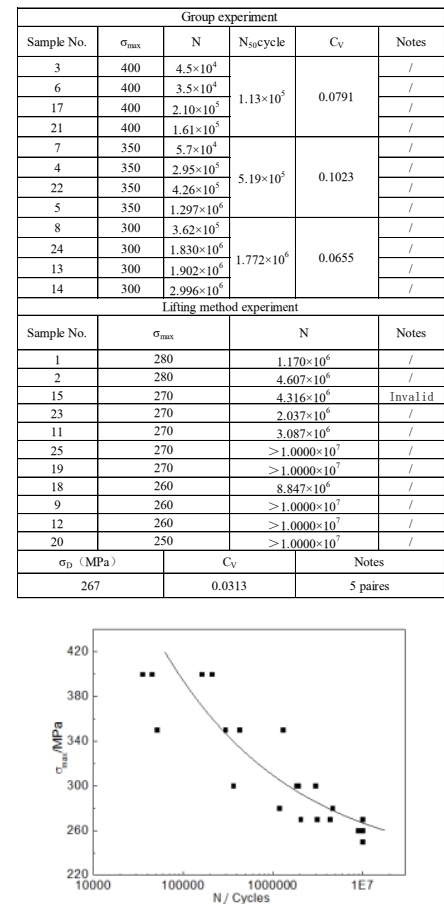

Fig $5 \mathrm{~S}-\mathrm{N}$ curve $\left(\mathrm{K}_{\mathrm{t}}=3, \mathrm{R}=0.06\right)$

\section{Discussion}

\subsection{Effect of $R$ on Fatigue Properties}

Comparing to the fatigue properties of the material under different $\mathrm{R}$ conditions, it can be seen that when the maximum stress is $900 \mathrm{MPa}$, the fatigue life of the material is $2.58 \times 10^{5}$ under condition of $\mathrm{R}=0.5$ and which is $3.4 \times 10^{4}$ when the stress ratio $\mathrm{R}=0.06$. When the maximum stress is $800 \mathrm{MPa}$, the fatigue life is $1.108 \times 10^{6}$ when $\mathrm{R}=0.5$ and $1.4 \times 10^{5}$ when $\mathrm{R}=0.06$. At the same time, the fatigue ultimate strength also decreased from 626 MPa to $527.5 \mathrm{MPa}$. The fatigue limit of materials reflects the comprehensive ability of materials to resist crack initiation and propagation. Which shows that the greater the stress ratio, the greater the fatigue life of the material, and the greater the impact on the fatigue ultimate strength.

\subsection{Effect of $K_{t}$ on Fatigue Properties}

Comparing to the fatigue properties of the material under different $\mathrm{K}_{\mathrm{t}}$ conditions, it can be seen that when $\mathrm{K}_{\mathrm{t}}=3, \sigma_{\mathrm{D}}$ is $267 \mathrm{MPa}$, which is about $1 / 2$ of the value when $\mathrm{K}_{\mathrm{t}}=1$. The fatigue property of the material is greatly affected by Kt. When the specimen is changed from smooth to notched, the fatigue limit loss of the material is 
very large.

\subsection{High cycle fatigue fracture characteristics}

The fracture characteristics of fatigue fracture are analyzed. The macro fracture morphology is divided into three distinct regions, including the crack source, the crack growth regione and the final rupture region In this experiment, when $\mathrm{K}_{\mathrm{t}}=1$, both in high and low stress regions, cracks begin to initiate and propagate on the surface, and the location of the initiation is relatively clear. When $\mathrm{K}_{t}=3$, there are multiple fatigue crack initiation points. Radial river patterns can be clearly seen near the germination point.

The fatigue band is a groove pattern which is slightly curved and parallel to each other. It is perpendicular to the direction of crack propagation. It is the microcosmic trace left by crack propagation and the most typical microcosmic feature of fatigue fracture. There are obvious fatigue bands in the crack propagation zone. The fatigue bands are fine under low stress. Grain boundary plays an important role in the fatigue crack propagation. The crack front is blocked near the grain boundary, and the striation direction changes when the crack transits from one grain to the adjacent one. Under high stress, the crack propagation is faster, the fatigue strip bandwidth is wider, and the crystallographic characteristics of the stripe are not obvious ${ }^{[6]}$.

In the high stress region $\left(\sigma_{\max }=900 \mathrm{MPa}\right)$, near the fatigue source region, the fracture morphology has slip steps and cleavage characteristics, and the cyclic loading times are few, and the fatigue band characteristics are not obvious, shown in Fig.6. In the medium stress region ( $\sigma$ $\max =600 \mathrm{MPa}$ ), the crack growth area is large and the fatigue band characteristics are obvious, shown in Fig.7. In the low stress region $\left(\sigma_{\max }=300 \mathrm{MPa}\right)$, the crack initiation point increases and the fatigue band characteristics are obvious, shown in Fig.8. The instantaneous fracture zone, i.e. the area formed by the unstable propagation of the crack, presents dimples, which belongs to the typical ductile fracture characteristics. As the stress decreases, the area of fatigue crack growth zone increases.

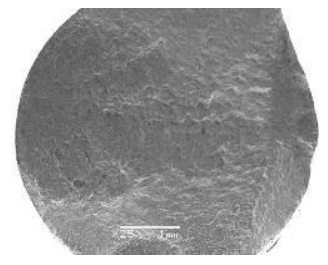

(a) Macroscopic morphology

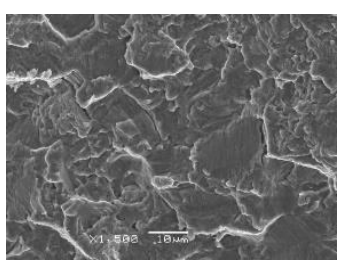

(c) crack growth region

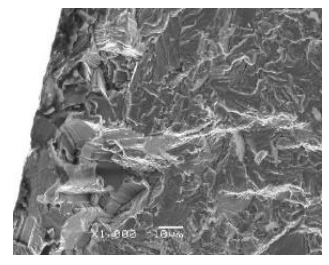

(b) crack source

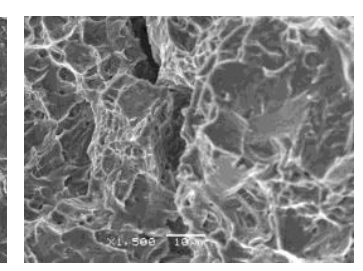

(d) final rupture region
Fig.6 Fracture morphology $\left(\mathrm{Kt}=1, \mathrm{R}=0.06, \quad \sigma_{\max }=900 \mathrm{MPa}\right)$

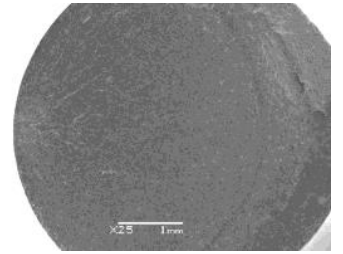

(a) Macroscopic morphology

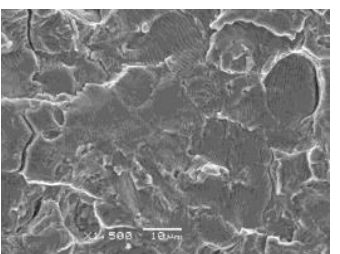

(c) crack growth region

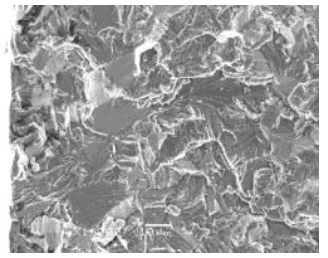

(b) crack source region

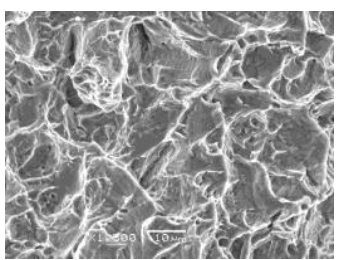

(d) final rupture region
Fig.7 Fracture morphology $\left(\mathrm{Kt}=1, \mathrm{R}=0.06, \quad \sigma_{\max }=600 \mathrm{MPa}\right)$

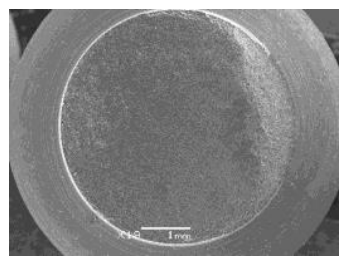

(a) Macroscopic morphology

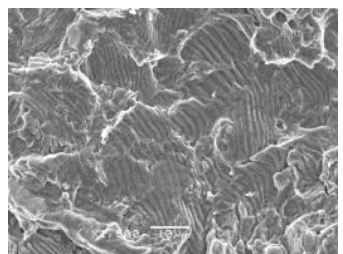

(c) crack growth region

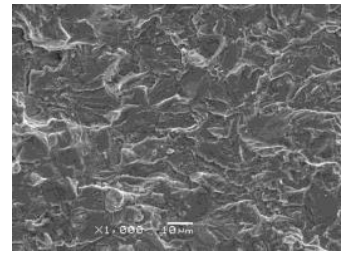

(b) crack source region

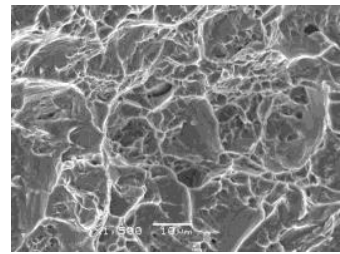

(d) final rupture region
Fig.8 Fracture morphology $\left(\mathrm{Kt}=3, \mathrm{R}=0.06, \quad \sigma_{\max }=300 \mathrm{MPa}\right)$

\section{Conclusion}

(1) $\mathrm{R}$ has a great influence on the fatigue properties of WSTi6211 titanium alloy. With the increase of R, the_D of the material increases. When $R$ increases from 0.06 to 0.5 , the corresponding_D increases from $527.5 \mathrm{MPa}$ to $626 \mathrm{MPa}$. 
(2) Kt has a great influence on fatigue properties of WSTi6211 titanium alloy. When Kt increases from 1 to 3 , the corresponding_D decreases from $527.5 \mathrm{MPa}$ to about $50 \%$.

(3) The fracture morphology shows typical fatigue fracture morphology. The crack initiation point is more than the sample surface, and there are typical fatigue bands. With the decrease of stress, the area of crack propagation area increases.

\section{Acknowledgements}

Thank my tuter, classmates and colleagues and they gave me lots help during experiments.

\section{Reference:}

[1] Cao Chunxiao. Generation Material Technology, Generation Large Aircraft [J]. Acta Aeronautica ET Astronautica Sinica. 2008, 29(3): 701-706.

[2]Li Xingwu,Liu Ruiming,Sha Aixue,Chu Junpeng etc. EFFECT OF MICROSTRUCTURE ON FATIGUE PROPERTIES OF TA15 ALLOY [J]. Acta Metallurgica Sinica, 2002, 38(supplementary issue):280-281.

[3]CAO Jing-xia,HUANG Xu, LI Zhen-xi, High Cycle Fatigue Properties and Fracture Features of TA15 Titanium Alloy[J], Journal of Materials Engineering, 2004.3 (3) : 28-34

[4]J A Hines, G lutjering. Propagation of microcracks at stress amplitudes below the convertional fatigue limit in Ti-6Al-4V[J].Fatigue Fract Eng Mater Sruct,1999,22(8):657-666

[5]A L Dowson,C J Beevers and L Grabowski.The Microstructual Features Associated with the Growth of Short Fatigue Cracks in a Near-Alpha Ti Alloy[A].F H Fores and I Caplan.Titanium Science and Technology[C].TMS.1993.1741-1748
[6]G Lutjering.Influence of Processing on Microstructure and Mechanical Properties of $(\alpha+\beta)$ Titanium Alloys[J].Mat Sci Eng,1998.A243:32-45.

[7] W J Evans.Optimising Mechenical Properties in Alpha+Beta Titanium Alloys[J]. Mat Sci Eng,1998,A243:89-96.

[8] M Ya Brun, G V Shakhanova,Titanium Alloy Structure and Pramaters Defining Its Diversity[J],Titanium Science Technical Journal,1993,1 (3): $24-29$ 